\title{
Anaemia, iron deficiency and vitamin A status among school-aged children in rural Kazakhstan
}

\author{
Masahiro Hashizume ${ }^{1,2, *}$, Momoko Chiba ${ }^{3}$, Atsuko Shinohara ${ }^{3}$, Shigehiro Iwabuchi ${ }^{4}$, \\ Satoshi Sasaki ${ }^{5}$, Taeko Shimoda ${ }^{6}$, Osamu Kunii ${ }^{7}$, Wathan Caypil ${ }^{8}$, Damir Dauletbaev ${ }^{9}$ \\ and Akmaral Alnazarova ${ }^{10}$ \\ 'Department of International Community Health, Graduate School of Medicine, The University of Tokyo, Tokyo, \\ Japan: ${ }^{2}$ Public and Environmental Health Research Unit, London School of Hygiene and Tropical Medicine, Keppel \\ Street, London WC IE 7HT, UK: ${ }^{3}$ Department of Epidemiology and Environmental Health, Juntendo University School \\ of Medicine, Tokyo, Japan: ${ }^{4}$ Central Research Laboratories, Nippon Zenyaku Kogyo, Koriyama-City, Japan: \\ ${ }^{5}$ National Institute of Health and Nutrition, Tokyo, Japan: ${ }^{6}$ Faculty of Home Economics, Kyushu Women's University, \\ Kitakyushu, Japan: ${ }^{7}$ Research and Programming Division, Economic Cooperation Bureau, Ministry of Foreign \\ Affairs, Tokyo, Japan: ${ }^{8}$ Department of Biochemistry, Kazakh State Medical University, Almaty, Kazakhstan: \\ ${ }^{9}$ State Medical Centre, Kzyl-Orda City, Kazakhstan: ${ }^{10}$ Health Care Department, Kzyl-Orda State, Kzyl-Orda, \\ Kazakhstan
}

Submitted 16 June 2004: Accepted 9 December 2004

\begin{abstract}
Objectives: To investigate the prevalence of anaemia and iron deficiency and vitamin A status among school-aged children in rural Kazakhstan and identify factors associated with anaemia in this population.

Design: A cross-sectional design.

Setting: School-aged children in rural Kazakhstan.

Subjects: Socio-economic and anthropometric information was collected from 159 school-aged children living in the Kzyl-Orda region of Kazakhstan. Blood samples were collected and the concentrations of haemoglobin $(\mathrm{Hb})$, serum iron, serum ferritin (SF), erythrocyte protoporphyrin (EP), serum retinol and $\beta$-carotene, total iron binding capacity (TIBC), transferrin saturation (TS) and other haematological indices were measured.

Results: Among the 159 children, the prevalence of anaemia and iron deficiency defined by the multiple criteria model (SF, TS and EP) was $27 \%$ and $13 \%$, respectively. Nine per cent had iron-deficiency anaemia and $21 \%$ had serum retinol value $<1.05 \mu \mathrm{moll}^{-1}$. Mean SF and serum iron concentrations and TS were significantly lower in anaemic children than in their non-anaemic peers, while TIBC and EP were significantly higher in children with anaemia. Hb was significantly correlated with serum iron and retinol concentrations. Serum retinol and SF concentrations and mean corpuscular volume were significantly correlated with $\mathrm{Hb}$ by multiple regression analysis.

Conclusions: Anaemia among school-aged children in rural Kazakhstan appears to be related to iron indices and vitamin A status.
\end{abstract}

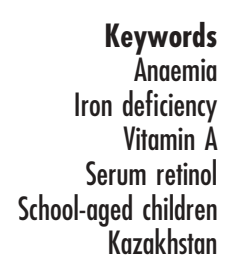

Iron-deficiency anaemia is a major nutritional problem throughout the world and leads to serious health problems, such as poor cognitive and motor development and behavioural problems, in children ${ }^{1}$. The Demographic and Health Surveys in Kazakhstan ${ }^{2}$ reported that $69 \%$ of children younger than 3 years were anaemic. However, information to examine the aetiology of anaemia is very limited in Kazakhstan and other Central Asian republics ${ }^{3}$. In a previous study in rural Kazakhstan, we observed a positive correlation between serum ferritin (SF) and haemoglobin $(\mathrm{Hb})$ concentrations, suggesting that a significant proportion of anaemia cases might be related to iron deficiency ${ }^{4}$. Another study showed that higher iron intake is associated with a decreased prevalence of anaemia 5 . However, only one-third of the incidence of anaemia in this population could be attributed to iron deficiency ${ }^{4}$ and it is possible that other important factors influence the prevalence of anaemia in the region.

Many nutritional surveys from around the world have shown a close association between vitamin A deficiency 
and anaemia ${ }^{6,7}$. There is clear evidence of an association between serum retinol and iron indicators ${ }^{8-10}$, and vitamin A deficiency is considered among the causes of anaemia $^{11}$. Vitamin A is thought to influence anaemia by modulating erythropoiesis and iron metabolism and by enhancing immunity to infection and the anaemia of infection $^{11}$. The effect of poor vitamin A status on irondeficiency anaemia could have widespread implications for current preventive public health interventions ${ }^{11}$. However, there is very limited information on vitamin A status in Kazakhstan and other Central Asian republics. In the present paper we report on a community-based study assessing the prevalence of anaemia and iron deficiency, and vitamin A status, among school-aged children in rural Kazakhstan. We also explored various factors associated with anaemia in this population.

\section{Subjects and methods}

\section{Subjects}

This study was conducted as part of a follow-up study to assess the incidence of anaemia in school-aged children 2 years after a baseline study. Detailed descriptions of the study site and the sampling procedures of the baseline study appear elsewhere ${ }^{4}$. Briefly, equal numbers of boys and girls born between 1985 and 1993 inclusive (8-17 years old at the time of the study) were randomly selected according to birth year from the list of children in nine villages in the Kazalinsk district of the Kzyl-Orda region. From 380 subjects enrolled in the larger baseline study, we selected all 208 participants living in five villages in the Kazalinsk district. The villages were selected as representative of the geographical distribution of villages in the district. Mothers of eligible children were invited to bring their children to the health centre on a designated day. A total of 164 children were enrolled in the study, giving a response rate of $79 \%$. A complete set of haematological and anthropometric data was obtained from 159 children. The research protocol was reviewed and approved by the institutional ethical committee of Juntendo University School of Medicine and the Ministry of Health in KzylOrda region. Children participating in the study and their parents were well informed about the research and the parents gave their written consent.

\section{Questionnaire}

A questionnaire was developed to obtain information on the family's socio-economic and demographic status such as household size, income and possessions, parents' education and the vegetables and fruits grown in the home garden at the time of interviews. Number of varieties of vegetables and fruits grown in the home garden was calculated by summing the vegetables and fruits grown in the home garden. Local nurses of public hospitals interviewed the children's mothers or guardians at the health centres using the questionnaire written in the Kazakh language.

\section{Anthropometry}

Anthropometric measurement was based on the standardised method of the World Health Organization (WHO) and the United Nations Children's Fund ${ }^{12,13}$. The weight of children, wearing minimal clothing, was measured to the nearest $0.1 \mathrm{~kg}$ on a battery-powered digital scale. Height was measured to the nearest $0.1 \mathrm{~cm}$ with a scale with a movable bar and steel tape. Height-for-age and weightfor-age were expressed in $Z$-scores and calculated with Epi Info 2000 (Centers for Disease Control and Prevention, Atlanta, GA, USA) with use of the National Center for Health Statistics reference data ${ }^{14}$. Stunting was defined following the WHO definition ${ }^{15}$ as height-for-age $Z$-score below -2 . Body mass index (BMI; weight in kg divided by the square of height in $\mathrm{m}$ ) less than the 5 th percentile according to the sex- and race-specific tables of Must et al. ${ }^{16,17}$ was used to define wasting.

\section{Blood sampling and biochemical measurements}

A blood sample $(7 \mathrm{ml})$ was collected by venepuncture of an antecubital vein. One millilitre was drawn into a container with ethylenediaminetetraacetic acid to measure white blood cell (WBC) and red blood cell (RBC) counts, $\mathrm{Hb}$ concentration, haematocrit (Hct), mean corpuscular volume (MCV), mean corpuscular haemoglobin (MCH) and mean corpuscular haemoglobin concentration (MCHC). Assays were performed immediately after blood sampling using an automated cell counter (MEK5207 Hematology Analyzer; Nihon Kohden, Tokyo, Japan). Another $1 \mathrm{ml}$ of blood was placed in a tube containing heparin and wrapped with foil to protect against photodecomposition of protoporphyrins. The remaining blood was centrifuged at $3000 \boldsymbol{g}$ for $5 \mathrm{~min}$ at room temperature. The sera and blood specimens were immediately frozen at $-10^{\circ} \mathrm{C}$, kept for $1-3$ weeks and then transported to Tokyo in a portable ice box filled with solid carbon dioxide. Then all specimens were kept frozen at $-80^{\circ} \mathrm{C}$ until analyses.

Serum retinol and $\beta$-carotene levels were determined simultaneously using high-performance liquid chromatography (HPLC). The procedure followed the method of Miller and Yang ${ }^{18}$ with slight modification. Retinol and $\beta$-carotene were extracted with hexane after deproteinisation with ethanol containing retinyl acetate as the internal standard, and evaporated to dryness under nitrogen gas. The residue was dissolved in $1.0 \mathrm{ml}$ ethanol. A portion $(50 \mu \mathrm{l})$ of the sample was injected into the column (Shim Pack CLC-ODS, $6.0 \mathrm{~mm} \times 150 \mathrm{~mm}$ ) installed with the HPLC apparatus (LC-VP Series; Shimadzu, Kyoto, Japan). The mobile phase was a methanol-chloroform mixture (87:15). Concentrations of retinol and $\beta$-carotene were determined by spectrophotometry (SPD-10AV instrument; Shimadzu) at $325 \mathrm{~nm}$ for retinol and $453 \mathrm{~nm}$ for 
$\beta$-carotene. The intra-assay coefficients of variation for retinol and $\beta$-carotene were $0.6 \%$ and $2.7 \%$, respectively.

Erythrocyte protoporphyrin (EP) concentrations were determined according to the previously reported method $^{19}$. Protoporphyrins in $50 \mu \mathrm{l}$ whole blood were

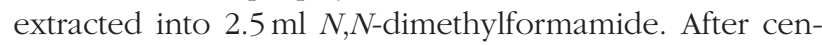
trifugation at $3000 \mathrm{rev} \mathrm{min}^{-1}$ for $5 \mathrm{~min}, 20 \mu \mathrm{l}$ supernatant was injected into the column (JASCO Fine Pak (C18) $4.6 \mathrm{~mm} \times 150 \mathrm{~mm}$; pre-column Biofine $4.6 \mathrm{~mm} \times 10 \mathrm{~mm}$; JASCO, Tokyo Japan) of an HPLC apparatus (RF-535; Shimadzu). The mobile phase was mixture of acetonitrileacetic acid-200 mM ammonium acetate (90:5:5) at pH 5.2. Zinc protoporphyrin and free protoporphyrin were determined separately; emission wavelength was $590 \mathrm{~nm}$ for zinc protoporphyrin and $630 \mathrm{~nm}$ for free protoporphyrin (Hitachi 320 Spectrofluorometer, Tokyo, Japan). Total free EP concentrations were calculated as free protoporphyrin concentration + zinc protoporphyrin concentration/1.1.

SF concentration was determined by the electrochemiluminescence immunoassay method enhanced with magnetic capture on an Elecsys 2010 Immunoassay Analyser (Hitachi High-Technology Corporation, Tokyo, Japan). The intra-assay coefficient of variation for SF was $4.8 \%$. Transferrin saturation (TS) was determined by dividing the serum iron concentration by the total ironbinding capacity (TIBC) as assessed by a colorimetric procedure $^{20}$. C-reactive protein (CRP) concentration was measured by using a latex turbidimetric immunoassay method with a commercial kit (CRP-Latex Seiken; Denka Seiken Co., Ltd, Tokyo, Japan). The intra-assay coefficient of variation for CRP was $1.2 \%$. The laboratory personnel who measured EP and serum retinol and $\beta$-carotene concentrations were not aware of the anaemic status of study participants.

On the basis of a multiple criteria model, iron deficiency was defined when abnormal results were found for two or more of the three tests: SF, TS and EP. Values were considered abnormal if $<12 \mu \mathrm{g} \mathrm{dl}^{-1}$ for SF, $<16 \%$ for TS and $>70 \mu \mathrm{g} \mathrm{dl}^{-1}$ for $\mathrm{EP}^{20}$. Iron-deficiency anaemia was defined as iron deficiency concurrent with anaemia. Anaemia was defined as $\mathrm{Hb}$ concentration below the cutoff for age and sex as defined by WHO $\left(12 \mathrm{~g} \mathrm{dl}^{-1}\right.$ for females and 8-14-year-old males and $13 \mathrm{~g} \mathrm{dl}^{-1}$ for 15-17-year-old males) ${ }^{21}$. CRP concentration and WBC count were used as indicators of the presence of a possible infection or inflammation. CRP concentration $>5.0 \mathrm{mgl}^{-1}$ and WBC count $>10000 / \mathrm{mm}^{3}$ were considered abnormal.

\section{Statistical analysis}

The distribution of each set of data was tested for normality before analysis, using the KormogorovSmirnov goodness-of-fit test. Where necessary, data were normalised using natural-log transformations. Means, standard deviations (SD) and medians were calculated for each variable. Chi-square tests were used to compare categorical variables between groups. Differences in continuous variables between groups were examined by using Student's $t$-test. Pearson's correlation test was performed to examine the association between concentrations of serum retinol and $\beta$-carotene and measures of iron status. Backward-stepwise multiple regression analysis was performed to assess the independent relationship of $\mathrm{Hb}$ concentration with various socio-economic and biochemical factors. Statistical significance was set at $P<0.05$. SPSS for Windows version 10.0 (SPSS Inc., Chicago, IL, USA, 1999) was used for statistical analysis.

\section{Results}

Socio-economic and demographic characteristics of the subjects are presented in Table 1 . The sample comprised approximately equal numbers of boys and girls between the ages of 8 and 17 years inclusive. All the children were Muslim and Kazakh in origin. The percentage of parents who did not complete primary or secondary education (10 years of school) was low (5\%). Despite this high education level, parents' unemployment rate was high. The median monthly household income (including

Table 1 Socio-economic and demographic characteristics of school-aged children in rural Kazakhstan $(n=159)$

\begin{tabular}{|c|c|c|}
\hline Variable & $n$ & $(\%)$ \\
\hline \multicolumn{3}{|l|}{ Sex } \\
\hline Boy & 83 & (52.2) \\
\hline Girl & 76 & $(47.8)$ \\
\hline \multicolumn{3}{|l|}{ Age group (years) } \\
\hline $8-10$ & 47 & $(29.6)$ \\
\hline $11-13$ & 56 & (35.2) \\
\hline $14-17$ & 56 & (35.2) \\
\hline \multicolumn{3}{|l|}{ Household size (persons) } \\
\hline Up to 4 & 13 & $(8.2)$ \\
\hline $5-7$ & 112 & $(70.4)$ \\
\hline Over 7 & 34 & $(21.4)$ \\
\hline \multicolumn{3}{|l|}{ Mother's education } \\
\hline Primary/secondary incomplete (0-9 years) & 8 & $(5.0)$ \\
\hline Primary/secondary complete (10 years) & 90 & $(56.6)$ \\
\hline High $(>10$ years) & 61 & (38.4) \\
\hline \multicolumn{3}{|l|}{ Income and employment } \\
\hline Total income (Tenge)† & 7500 & $(6750)$ \\
\hline Father unemployed & 47 & $(29.6)$ \\
\hline \multicolumn{3}{|c|}{ Vegetables and fruits planted in home garden $(n=115)$} \\
\hline Melons & 85 & $(73.9)$ \\
\hline Cucumbers & 84 & $(73.0)$ \\
\hline Tomatoes & 82 & $(71.3)$ \\
\hline Onions & 75 & $(65.2)$ \\
\hline Watermelons & 67 & (58.3) \\
\hline Carrots & 65 & $(56.5)$ \\
\hline Potatoes & 52 & $(45.2)$ \\
\hline Grapes & 22 & $(19.1)$ \\
\hline Sweet peppers & 20 & (17.4) \\
\hline Apples & 14 & (12.2) \\
\hline Aubergines & 13 & (11.3) \\
\hline Berries & 11 & $(9.6)$ \\
\hline Nuts, seeds & 0 & $(0.0)$ \\
\hline Other fresh fruits or vegetables & 57 & $(49.6)$ \\
\hline
\end{tabular}


government benefits) was 7500 Tenge, equivalent to US\$53 (August 2002).

The anthropometric and biochemical indices included in the nutritional assessment are presented in Table 2. Of all children in the study, $11 \%$ exhibited stunted growth and $15 \%$ were wasted. There was no difference in the prevalence of stunting between age groups, but the prevalence of wasting was significantly different between age groups ( $26 \%$ for $8-10$-year-olds, $20 \%$ for $11-13$-yearolds and $0 \%$ for 14-17-year-olds; $P<0.001)$.

Mean $( \pm \mathrm{SD}) \mathrm{Hb}$ concentration was $12.6 \pm 1.0 \mathrm{~g} \mathrm{dl}^{-1}$ in boys and $12.3 \pm 1.5 \mathrm{~g} \mathrm{dl}^{-1}$ in girls. The prevalence of anaemia was $27 \%$. Age group-specific anaemia rates were $15 \%$ for $8-10$-year-olds, $23 \%$ for $11-13$-year-olds and $41 \%$ for $14-17$-year-olds $(P=0.009)$. Using a cut-off value of $12 \mu \mathrm{gl}^{-1}$ for SF concentration, $16 \%$ of the children were iron-depleted, while TS was decreased $(<16 \%)$ in $37 \%$ of the children. In contrast, only one subject had an elevated EP concentration $\left(>70 \mu \mathrm{g} \mathrm{dl}^{-1}\right)$. There were no differences in the prevalence of abnormal values of these ironstatus indices between boys and girls. The prevalence of low SF values was significantly different between age groups ( $2 \%$ for $8-10$-year-olds, $18 \%$ for $11-13$-year-olds and $25 \%$ for $14-17$-year-olds; $P=0.006$ ). The prevalence of iron deficiency, based on the multiple criteria model, was $13 \%$, and the prevalence of iron-deficiency anaemia was 9\%. Among the children with normal Hb levels, 5\% were iron-deficient.

The mean serum retinol concentration was $1.4 \mu \mathrm{moll}^{-1}$. Twenty-one per cent of the children had serum retinol values $<1.05 \mu \mathrm{moll}^{-1}$ and only one child had a serum retinol value $<0.70 \mu \mathrm{moll}^{-1}$. The median $\beta$-carotene concentration was $18.4 \mu \mathrm{g} \mathrm{dl}^{-1}$.

Thirteen subjects (8\%) had high CRP concentration $\left(>5.0 \mathrm{mgl}^{-1}\right)$ or WBC count $\left(>10000 / \mathrm{mm}^{3}\right)$. They were excluded from the statistical analysis of the relationship between vitamin A status and iron indices, because acute infection or inflammatory processes may influence these relationships ${ }^{22,23}$.

The relationships between anaemia, iron status and vitamin A indices are shown in Table 3. Children were divided into two groups based on the presence or absence of anaemia. Serum retinol and $\beta$-carotene concentrations were not associated with anaemic status. Some evidence suggested that the proportion with serum retinol concentration $<1.05 \mu \mathrm{mol}^{-1}$ was higher in children with anaemia

Table 2 Anthropometric and haematological indices of school-aged children in rural Kazakhstan $(n=159)$

\begin{tabular}{|c|c|c|c|c|c|c|}
\hline \multirow[b]{2}{*}{ Variable } & \multicolumn{3}{|c|}{ Boys $(n=83)$} & \multicolumn{3}{|c|}{ Girls $(n=76)$} \\
\hline & Mean & SD & Median & Mean & SD & Median \\
\hline \multicolumn{7}{|l|}{ Anthropometry } \\
\hline Height-for-age Z-score & -0.97 & 0.91 & -0.91 & -0.96 & 0.91 & -0.98 \\
\hline Weight-for-age Z-score & -0.78 & 0.78 & -0.84 & -0.89 & 0.84 & -1.04 \\
\hline Body mass index $\left(\mathrm{kg} \mathrm{m}^{-2}\right)$ & 17.8 & 2.0 & 17.7 & 17.7 & 3.2 & 17.2 \\
\hline Stunting, $n(\%) \dagger$ & & $11(12.8)$ & & & $6(7.9)$ & \\
\hline Wasting, $n(\%) \ddagger$ & & $9(10.5)$ & & & $14(18.4)$ & \\
\hline \multicolumn{7}{|l|}{ Blood analysis } \\
\hline Red blood cells $\left(\times 10^{4} / \mathrm{mm}^{3}\right)$ & 503 & 43 & 496 & 488 & 42 & 485 \\
\hline Haemoglobin $\left(\mathrm{g} \mathrm{dl}^{-1}\right)$ & 12.6 & 1.0 & 12.7 & 12.3 & 1.5 & 12.6 \\
\hline Haematocrit (\%) & 44.7 & 4.1 & 44.0 & 43.8 & 4.7 & 44.6 \\
\hline Mean corpuscular volume (fl) & 88.9 & 5.2 & 90.0 & 89.9 & 8.0 & 90.0 \\
\hline Mean corpuscular haemoglobin (pg) & 25.2 & 2.0 & 25.4 & 25.2 & 2.9 & 25.5 \\
\hline Mean corpuscular haemoglobin concentration $\left(\mathrm{g} \mathrm{dl}^{-1}\right)$ & 28.3 & 1.4 & 28.3 & 28.0 & 1.5 & 28.1 \\
\hline Serum ferritin $\left(\mu \mathrm{gl}^{-1}\right)$ & 33.7 & 20.0 & 30.0 & 33.5 & 46.9 & 25.5 \\
\hline Serum iron $\left(\mu \mathrm{g} \mathrm{dl}^{-1}\right)$ & 69.0 & 29.0 & 70.0 & 67.0 & 36.3 & 66.5 \\
\hline Serum total iron-binding capacity $\left(\mu \mathrm{g} \mathrm{dl}^{-1}\right)$ & 362.3 & 54.2 & 356.0 & 380.3 & 52.5 & 377.0 \\
\hline Transferrin saturation (\%) & 19.6 & 8.3 & 20.3 & 18.4 & 11.4 & 17.8 \\
\hline Erythrocyte protoporphyrin $\left(\mu \mathrm{g} \mathrm{dl}^{-1}\right)$ & 18.0 & 8.5 & 15.6 & 19.6 & 12.9 & 16.1 \\
\hline Serum retinol $\left(\mu \mathrm{mol}^{-1}\right)$ & 1.4 & 0.3 & 1.3 & 1.4 & 0.4 & 1.3 \\
\hline Serum $\beta$-carotene $\left(\mu \mathrm{g} \mathrm{dl}^{-1}\right)$ & 20.7 & 11.1 & 18.4 & 23.0 & 14.9 & 18.5 \\
\hline \multicolumn{7}{|l|}{ Anaemia, $n(\%) \S$} \\
\hline Mild & & $21(25.3)$ & & & $14(18.4)$ & \\
\hline Moderate & & $2(2.4)$ & & & $4(5.3)$ & \\
\hline Severe & & $0(0.0)$ & & & $2(2.6)$ & \\
\hline Iron deficiency, $n(\%) \emptyset$ & & $7(8.4)$ & & & $13(17.1)$ & \\
\hline \multicolumn{7}{|l|}{ Vitamin A deficiency, $n(\%)$} \\
\hline Serum retinol $<1.05 \mu \mathrm{moll}^{-1}$ & & $15(18.1)$ & & & $18(23.7)$ & \\
\hline Serum retinol $<0.70 \mu \mathrm{moll}^{-1}$ & & $0(0.0)$ & & & $1(1.3)$ & \\
\hline
\end{tabular}

SD - standard deviation.

† Height-for-age $Z$-score $<-2$.

$\ddagger$ Body mass index below the 5 th percentile of the reference population ${ }^{16,17}$.

$\S$ Mild anaemia - haemoglobin $(\mathrm{Hb})$ concentration above $10.0 \mathrm{~g} \mathrm{dl}^{-1}$ but below $12.0 \mathrm{~g} \mathrm{dl}^{-1}$ for females and $8-14$-year-old males or above $10.0 \mathrm{~g} \mathrm{dl}-1$ but below $13.0 \mathrm{~g} \mathrm{dl}^{-1}$ for $15-17$-year-old males; moderate anaemia $-\mathrm{Hb}$ between 7.0 and $10.0 \mathrm{~g} \mathrm{dl}^{-1}$; severe anaemia $-\mathrm{Hb}$ below $7.0 \mathrm{~g} \mathrm{dl}{ }^{-1}$.

I Abnormal values for two or more of three iron-status indicators: ferritin $\left(<12 \mu \mathrm{g} \mathrm{dl}^{-1}\right)$, transferrin saturation $(<16 \%)$ and erythrocyte protoporphyrin $\left(>70 \mu \mathrm{g} \mathrm{dl}^{-1}\right)$. 
Table 3 Mean values for biochemical indices by anaemic status of school-aged children in rural Kazakhstan $(n=146)$

\begin{tabular}{|c|c|c|c|c|c|}
\hline \multirow[b]{2}{*}{ Variable } & \multicolumn{2}{|c|}{ Anaemic $†(n=40)$} & \multicolumn{2}{|c|}{$\begin{array}{c}\text { Non-anaemic } \\
(n=106)\end{array}$} & \multirow[b]{2}{*}{$P$-value } \\
\hline & Mean & SD & Mean & SD & \\
\hline Haematocrit (\%) & 40.2 & 4.4 & 45.8 & 3.4 & $<0.001$ \\
\hline Mean corpuscular volume (fl) & 85.8 & 9.1 & 90.7 & 5.2 & $<0.001$ \\
\hline Mean corpuscular haemoglobin (pg) & 23.6 & 3.4 & 25.8 & 1.7 & $<0.001$ \\
\hline Mean corpuscular haemoglobin concentration $\left(\mathrm{g} \mathrm{dl}^{-1}\right)$ & 27.3 & 1.6 & 28.5 & 1.3 & $<0.001$ \\
\hline Serum ferritin $\left(\mu \mathrm{gl}^{-1}\right)$ & 20.8 & 19.8 & 34.7 & 18.9 & $<0.001 \ddagger$ \\
\hline Serum iron $\left(\mu \mathrm{gdl}^{-1}\right)^{\prime}$ & 52.8 & 30.0 & 74.1 & 24.9 & $<0.001$ \\
\hline Serum total iron-binding capacity $\left(\mu \mathrm{g} \mathrm{dl}^{-1}\right)$ & 392.6 & 63.7 & 361.2 & 45.8 & 0.001 \\
\hline Transferrin saturation (\%) & 14.4 & 9.0 & 20.9 & 7.3 & $<0.001$ \\
\hline Erythrocyte protoporphyrin $\left(\mu \mathrm{g} \mathrm{dl}^{-1}\right)$ & 25.4 & 16.3 & 16.3 & 6.5 & $<0.001 \ddagger$ \\
\hline Serum retinol $\left(\mu \mathrm{moll}^{-1}\right)$ & 1.3 & 0.4 & 1.4 & 0.3 & 0.111 \\
\hline Serum retinol concentration $<1.05 \mu \mathrm{moll}^{-1}, n(\%)$ & \multicolumn{2}{|c|}{$12(30.0)$} & \multicolumn{2}{|c|}{$17(16.0)$} & $0.059 \S$ \\
\hline Serum $\beta$-carotene $\left(\mu \mathrm{g} \mathrm{dl}^{-1}\right)$ & 21.3 & 12.1 & 22.3 & 13.6 & $0.716 \ddagger$ \\
\hline
\end{tabular}

SD - standard deviation.

† Anaemia - $\mathrm{Hb}$ concentration below $12.0 \mathrm{~g} \mathrm{dl}^{-1}$ for females and 8-14-year-old males or below $13.0 \mathrm{~g} \mathrm{dl}^{-1}$ for $15-17$-year-old males.

$\ddagger$ Based on natural log-transformed values.

$\S$ Pearson chi-square test.

than in non-anaemic children $(P=0.059)$. Mean Hct, MCV, $\mathrm{MCH}, \mathrm{MCHC}$, TS and SF and serum iron concentrations were significantly lower in children with anaemia than in their non-anaemic peers. Serum TIBC and EP concentrations were significantly higher in children with anaemia.

Table 4 shows the partial correlation coefficients between different measures of $\mathrm{Hb}$ and vitamin $\mathrm{A}$ and iron-status indices adjusted for the effects of age, sex, BMI, household per capita income, years of parents' education, varieties of vegetables and fruits grown in the home garden and iron supplementation. Serum retinol concentration was significantly positively correlated with concentrations of serum iron and $\mathrm{Hb}$. There was a weak, negative correlation between serum retinol and EP concentrations, whereas $\beta$-carotene concentration was not significantly correlated with serum retinol or Hb levels or iron-status indices. Hb concentration was highly correlated with SF, serum iron and EP concentrations, TIBC and TS.

Backward-stepwise multiple regression analysis (Table 5) was used to identify the factors influencing $\mathrm{Hb}$ levels. The analysis included the variables age, sex, BMI, household per capita income, years of parents' education, varieties of vegetables and fruits grown in the home garden, iron supplementation, MCV, TS and concentrations of serum ferritin, EP, serum retinol and $\beta$-carotene. Using a $P$-value $>0.10$ for exclusion, serum retinol and $\mathrm{SF}$ concentrations and $\mathrm{MCV}$ were significantly related to $\mathrm{Hb}$ level. TS was weakly related to $\mathrm{Hb}$ concentration $(0.05<P<0.10)$. The overall $F$-ratio for all variables was $48.9(\mathrm{df}=4)$ and was highly significant $(P<0.001)$.

\section{Discussion}

We explored the prevalence of iron deficiency and anaemia, and vitamin A status, among school-aged children in rural Kazakhstan. To our knowledge, the relationships between iron deficiency, vitamin A deficiency and anaemia have not been well characterised among school-aged children. Our study is the first to report on vitamin A status in Kazakhstan and also on iron status based on the multiple criteria model in Kazakhstani children.

There are three stages in the development of irondeficiency anaemia ${ }^{20}$. The first stage is characterised by depletion of iron stores as reflected by a decline in $\mathrm{SF}$ concentration. The second phase, iron-deficient

Table 4 Partial correlation coefficients $\nmid$ for vitamin A and iron indices of school-aged children in rural Kazakhstan $(n=146)$

\begin{tabular}{|c|c|c|c|c|c|c|c|}
\hline Variable & SF $\ddagger$ & Serum Fe & Serum TIBC & TS & $\mathrm{EP} \ddagger$ & Serum retinol & Serum $\beta$-carotene $\ddagger$ \\
\hline $\mathrm{Hb}$ & $0.644^{\star \star \star}$ & $0.559^{\star \star \star}$ & $-0.323^{\star \star \star}$ & $0.529^{\star \star \star}$ & $-0.487^{\star \star \star}$ & $0.179^{* *}$ & -0.056 \\
\hline SF & - & $0.477^{\star \star \star}$ & $-0.599 * * *$ & $0.550^{\star \star *}$ & $-0.498^{\star \star \star}$ & 0.024 & -0.017 \\
\hline Serum Fe & - & - & $-0.312^{\star \star \star}$ & $0.956^{\star \star *}$ & $-0.450^{\star * \star}$ & $0.173^{\star \star}$ & 0.047 \\
\hline Serum TIBC & - & - & - & $-0.535^{\star \star *}$ & $0.490^{* \star *}$ & 0.115 & -0.005 \\
\hline TS & - & - & - & - & $-0.495^{\star \star \star}$ & 0.113 & 0.059 \\
\hline EP & - & - & - & - & - & $-0.162^{*}$ & 0.129 \\
\hline Serum retinol & - & - & - & - & - & - & 0.062 \\
\hline
\end{tabular}

SF - serum ferritin; TIBC - total iron-binding capacity; TS - transferrin saturation; EP - erythrocyte protoporphyrin; Hb - haemoglobin.

† Coefficient adjusted for age, sex, body mass index, household per capita income, years of parent's education, variety of vegetables and fruits grown in the home garden and iron supplementation.

$\ddagger$ Based on natural log-transformed values.

${ }^{\star}, P<0.1 ;{ }^{* \star}, P<0.05 ;{ }^{* \star \star}, P<0.01$. 
Table 5 Backward-stepwise multiple regression for haemoglobin concentration of schoolaged children in rural Kazakhstan $(n=146)$

\begin{tabular}{lccccr}
\hline Variable & $B$ & SE $B$ & Beta & $95 \%$ Cl for $B$ & $P$-value \\
\hline Mean corpuscular volume (fl) & 0.078 & 0.013 & 0.405 & $(0.053,0.102)$ & $<0.001$ \\
Serum ferritint $\left(\mu \mathrm{I}^{-1}\right)$ & 0.617 & 0.119 & 0.364 & $(0.381,0.852)$ & $<0.001$ \\
Serum retinol $\left(\mu \mathrm{mol}^{-1}\right)$ & 0.545 & 0.221 & 0.137 & $(0.109,0.981)$ & 0.015 \\
Serum transferrin saturation (\%) & 0.020 & 0.011 & 0.127 & $(-0.002,0.043)$ & 0.071 \\
\hline
\end{tabular}

$B$ - ordinary least-squares regression coefficient; SE $B$ - standard error of $B$; Beta - standardised $\beta$ coefficient; $\mathrm{Cl}$ - confidence interval.

Model summary: multiple $R=0.767 ; \quad R^{2}=0.588 ;$ adjusted $R^{2}=0.576 ; \quad F$-ratio $=48.9 \quad(\mathrm{df}=4)$; $P<0.001$.

†Based on natural log-transformed values.

erythropoiesis, is characterised by a decrease in TS and an increase in EP concentration. The final stage of iron deficiency is characterised by a reduction in the concentration of $\mathrm{Hb}$ in RBCs. The use of multiple indices of iron status provides a more accurate measure of iron status than any single index ${ }^{24}$.

In our study, $16 \%$ of the children had depleted iron stores ( $\mathrm{SF}<12 \mu \mathrm{gl}^{-1}$ ), 37\% exhibited iron-deficient erythropoiesis as defined by a reduction of TS $(<16 \%)$ and only one subject (0.6\%) had an elevated EP concentration $\left(>70 \mu \mathrm{g} \mathrm{dl}^{-1}\right)$. Because SF concentration is also elevated during infection or inflammation, some of our values could be false-negative results ${ }^{23}$. However, excluding those with elevated CRP concentration $\left(>5.0 \mathrm{mgl}^{-1}\right)$ or WBC count $\left(>10000 / \mathrm{mm}^{3}\right)$ from the analysis gave a similar percentage (16\%) of the children with iron-storage depletion. Fewer children had high EP concentration than had high TS. EP concentration can be in the normal range independent of iron deficiency (e.g. in thalassaemia) ${ }^{20,25}$. The proximity of the study site to the Caucasus region and Turkey, where the genetic condition of thalassaemia contributes to a high prevalence of anaemia ${ }^{26}$, warrants further study to determine whether a genetic predisposition for thalassaemia in Kazakhstani children may partly explain this discrepancy.

In our study, $27 \%$ of the children were anaemic and $9 \%$ had iron-deficiency anaemia. Our findings suggest that iron-deficiency anaemia is a public health problem among school-aged children in the area. However, using the strict criterion of abnormal results for two or more of the three tests (SF, TS and EP), we identified iron-deficiency anaemia in only one-third of all anaemic children, which was far less than we expected. When iron-deficiency anaemia was defined as anaemia plus low SF concentration, which might be more sensitive in detecting early depletion of body iron stores, the percentage increased slightly to $37 \%$ of all anaemic children. However, more than $60 \%$ of the cases with anaemia were not classified as iron-deficient.

We used multivariate analysis to determine whether iron status differed between anaemic and non-anaemic children. Anaemic children had significantly lower Hct, $\mathrm{MCV}, \mathrm{MCH}, \mathrm{MCHC}$, TS, and SF and serum iron concentrations, and higher serum TIBC and EP concentrations, compared with non-anaemic children, suggesting that iron status was likely to be an important determinant of $\mathrm{Hb}$ concentration and anaemia.

Our study showed that $21 \%$ of children had inadequate serum retinol values $\left(<1.05 \mu \mathrm{moll}^{-1}\right)$ and indicated significant correlations between concentrations of serum retinol and $\mathrm{Hb}$ and serum iron, indicating a possible relationship between vitamin A status and the use of iron for haematopoiesis. A positive correlation between $\mathrm{Hb}$ and serum or plasma retinol concentrations has been described in children in Guatemala ${ }^{8}$, Thailand ${ }^{7}$, Central

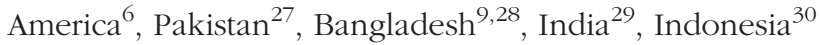
and Ethiopia ${ }^{31}$. Lower serum retinol concentration has also been associated with lower iron indices. For example, Ahmed et al. ${ }^{9}$ reported significant correlations between the concentrations of serum retinol, serum iron and $\mathrm{Hb}$, packed cell volume, MCHC and TS in adolescent girls in urban Bangladesh. Similar observations have also been reported in children less than 5 years of age ${ }^{8}$ and in school-aged children ${ }^{6}$.

The multiple regression analysis revealed that $\mathrm{Hb}$ concentration was independently associated with MCV and SF and serum retinol concentrations. There was a weak relationship between $\mathrm{Hb}$ concentration and TS. Accounting for other factors showed that for every $1 \mu \mathrm{moll}{ }^{-1}$ change in serum retinol concentration there is a $0.5 \mathrm{~g} \mathrm{dl}^{-1}$ change in $\mathrm{Hb}$ level. This effect is half of that reported by Ahmed et al. ${ }^{10}$, who found a $1.0 \mathrm{~g} \mathrm{dl}^{-1}$ change in $\mathrm{Hb}$ level in adolescent girls in Bangladesh. Our results may differ because we included both boys and girls and different age groups, and possibly because of residual confounding.

Because vitamin A is required for the effective utilisation of iron and for maintaining normal $\mathrm{Hb}$ concentration $^{8,32-36}$, the success of iron fortification or supplementation programmes is likely to vary according to vitamin A status. In 2001, Kazakhstan developed national plans for universal iron fortification of wheat flour ${ }^{37}$. Although this approach can be useful for promoting the anaemia prevention and control programme in Kazakhstan, our data reinforce the suggestion that programmes designed to reduce anaemia should also aim to improve vitamin A status. 


\section{Conclusions}

Our results suggest that anaemia among school-aged children in rural Kazakhstan cannot be explained solely by iron deficiency. Anaemia was independently related to vitamin A status as well. Programmes designed to reduce anaemia should also aim to improve vitamin A status in rural Kazakhstan.

\section{Acknowledgements}

We thank all the children and parents who participated in the survey. We also thank Dr Amangerdy Kadirbaev of the regional health authority and all local medical staff for making this investigation a reality. We express our gratitude to Ms Miwa Sekine, Juntendo University School of Medicine, Mr Yuichi Tachibana, Technician-in-Chief, Juntendo University Hospital and Mr Shoji Kumata, Nippon Zenyaku Kogyo, for their skilful techniques for blood analyses. We would like to thank Nihon Kohden Ltd for providing the Hematology Analyzer. For their advice and suggestions, we express our gratitude to Professor Norio Ishida, Kyoto University and Dr Kazunari Kaneko, Juntendo University School of Medicine. M.H. appreciates support given to him by Professor Susumu Wakai. This study was supported by a grant from the Toyota Foundation and a Grant-in-Aid for Scientific Research from the Japan Ministry of Education, Culture, Sports, Science and Technology.

\section{References}

1 Grantham-McGregor S, Ani C. A review of studies on the effect of iron deficiency on cognitive development in children. Journal of Nutrition 2001; 131(Suppl. 2): 649S-68S.

2 National Institute of Nutrition (Kazakhstan) \& Macro International Inc. Kazakbstan Demographic and Health Survey, 1995. Calverton, MD: National Institute of Nutrition and Macro International Inc., 1996.

3 World Health Organization (WHO). Complementary Feeding and the Control of Iron Deficiency Anaemia in the Newly Independent States. Copenhagen: WHO Regional Office for Europe, 2000.

4 Hashizume M, Kunii O, Sasaki S, Shimoda T, Wakai S, Mazhitova Z, et al. Anemia and iron deficiency among schoolchildren in the Aral Sea region, Kazakhstan. Journal of Tropical Pediatrics 2003; 49(3): 172-7.

5 Hashizume M, Shimoda T, Sasaki S, Kunii O, Caypil W, Dauletbaev D, et al. Anaemia in relation to low bioavailability of dietary iron among school-aged children in the Aral Sea region, Kazakhstan. International Journal of Food Sciences and Nutrition 2004; 55(1): 37-43.

6 Majia LA, Hodges RE, Arroyave G, Viteri F, Torun B. Vitamin A deficiency and anemia in Central American children. American Journal of Clinical Nutrition 1977; 30(7): 1175-84.

7 Bloem MW, Wedel M, Egger RJ, Speek AJ, Schrijver J, Saowakontha $\mathrm{S}$, et al. Iron metabolism and vitamin $\mathrm{A}$ deficiency in children in northeast Thailand. American Journal of Clinical Nutrition 1989; 50(2): 332-8.

8 Mejia LA, Arroyave G. The effect of vitamin A fortification of sugar on iron metabolism in preschool children in Guatemala. American Journal of Clinical Nutrition 1982; 36(1): 87-93.

9 Ahmed F, Khan MR, Karim R, Taj S, Hyderi T, Faruque MO, et al. Serum retinol and biochemical measures of iron status in adolescent schoolgirls in urban Bangladesh. European Journal of Clinical Nutrition 1996; 50(6): 346-51.

10 Ahmed F, Khan MR, Islam M, Kabir I, Fuchs GJ. Anaemia and iron deficiency among adolescent schoolgirls in peri-urban Bangladesh. European Journal of Clinical Nutrition 2000; 54(9): 678-83.

11 Semba RD, Bloem MW. The anemia of vitamin A deficiency: epidemiology and pathogenesis. European Journal of Clinical Nutrition 2002; 56(4): 271-81.

12 World Health Organization (WHO). Measuring Change in Nutritional Status. Guidelines for Assessing the Nutritional Impact of Supplementary Feeding Programmes for Vulnerable Groups. Geneva: WHO, 1983.

13 United Nations Children's Fund (UNICEF). How to Weigh and Measure Children: Assessing the Nutritional Status of Young Children in Household Surveys. New York: United Nations Department of Technical Co-operation for Development and Statistical Office, UNICEF, 1986.

14 Hamill PV, Drizd TA, Johnson CL, Reed RB, Roche AF, Moore WM. Physical growth: National Center for Health Statistics percentiles. American Journal of Clinical Nutrition 1979; 32(3): 607-29.

15 World Health Organization (WHO). The Use and Interpretation of Anthropometry. Technical Report Series. Geneva: WHO, 1995.

16 Must A, Dallal GE, Dietz WH. Reference data for obesity: 85th and 95th percentiles of body mass index $\left(\mathrm{wt} / \mathrm{ht}^{2}\right)$ and triceps skinfold thickness. American Journal of Clinical Nutrition 1991; 53(4): 839-46.

17 Must A, Dallal GE, Dietz WH. Reference data for obesity: 85th and 95th percentiles of body mass index $\left(\mathrm{wt} / \mathrm{ht}^{2}\right)$ and triceps skinfold thickness - a correction. American Journal of Clinical Nutrition 1991; 54: 773.

18 Miller KW, Yang CS. An isocratic high-performance liquid chromatography method for the simultaneous analysis of plasma retinol, $\alpha$-tocopherol, and various carotenoids. Analytical Biochemistry 1985; 145(1): 21-6.

19 Sakai K, Takeuchi S, Araki T, Ushio K, Kondo M, Chiba M, et al. Determination of protoporphyrins in blood using HPLC - standardization of protoporphyrins and interlaboratory comparison of analyses. Japanese Journal of Industrial Health 1992; 34: 236-42.

20 Gibson R. Assessment of iron status. In: Gibson R, ed. Principles of Nutritional Assessment. New York: Oxford University Press, 1990; 349-76.

21 De Maeyer EM. Preventing and Controlling Iron Deficiency Anemia through Primary Health Care. A Guide for Health Administrators and Programme Managers. Geneva: World Health Organization, 1989.

22 Thurnham DI, McCabe GP, Northrop-Clewes CA, Nestel P. Effects of subclinical infection on plasma retinol concentrations and assessment of prevalence of vitamin A deficiency: meta-analysis. Lancet 2003; 362(9401): 2052-8.

23 Hulthen L, Lindstedt G, Lundberg PA, Hallberg L. Effect of a mild infection on serum ferritin concentration - clinical and epidemiological implications. European Journal of Clinical Nutrition 1998; 52(5): 376-9.

24 Cook JD, Finch CA, Smith NJ. Evaluation of the iron status of a population. Blood 1976; 48(3): 449-55.

25 Stockman JA 3rd, Weiner LS, Simon GE, Stuart MJ, Oski FA. The measurement of free erythrocyte porphyrin (FEP) as a simple means of distinguishing iron deficiency from $\beta$-thalassemia trait in subjects with microcytosis. Journal of Laboratory and Clinical Medicine 1975; 85(1): 113-9.

26 United Nations Children's Fund (UNICEF)/World Health 
Organization (WHO). Prevention and Control of Iron Deficiency Anemia in Women and Children. Report of the UNICEF/WHO Regional Consultation. Geneva: WHO, 1999.

27 Molla A, Badruddin SH, Khurshid M, Molla AM, Rahaman FN, Durrani S, et al. Vitamin A status of children in the urban slums of Karachi, Pakistan, assessed by clinical, dietary, and biochemical methods. American Journal of Tropical Medicine and Hygiene 1993; 48(1): 89-96.

28 Ahmed F, Barua S, Mohiduzzaman M, Shaheen N, Bhuyan MA, Margetts BM, et al. Interactions between growth and nutrient status in school-age children of urban Bangladesh. American Journal of Clinical Nutrition 1993; 58(3): 334-8.

29 Mohanram M, Kulkarni KA, Reddy V. Hematological studies in vitamin A deficient children. International Journal for Vitamin and Nutrition Research 1977; 47(4): 389-93.

30 Semba RD, Muhilal, West KP Jr, Winget M, Natadisatra G, Scott A, et al. Impact of vitamin A supplementation on hematological indicators of iron metabolism and protein status in children. Nutrition Research 1992; 34: 469-78.

31 Wolde-Gebriel Z, Gebru H, Fisseha T, West CE. Severe vitamin A deficiency in a rural village in the Hararge region of Ethiopia. European Journal of Clinical Nutrition 1993; 47(2): 104-14.
32 van Stuijvenberg ME, Kruger M, Badenhorst CJ, Mansvelt EP, Laubscher JA. Response to an iron fortification programme in relation to vitamin A status in 6-12-year-old school children. International Journal of Food Sciences and Nutrition 1997; 48(1): 41-9.

33 Mejia LA, Chew F. Hematological effect of supplementing anemic children with vitamin A alone and in combination with iron. American Journal of Clinical Nutrition 1988; 48(3): 595-600.

34 Suharno D, West CE, Muhilal, Karyadi D, Hautvast JG. Supplementation with vitamin A and iron for nutritional anaemia in pregnant women in West Java, Indonesia. Lancet 1993; 342(8883): 1325-8.

35 Ahmed F, Khan MR, Jackson AA. Concomitant supplemental vitamin A enhances the response to weekly supplemental iron and folic acid in anemic teenagers in urban Bangladesh. American Journal of Clinical Nutrition 2001; 74(1): 108-15.

36 Tanumihardjo SA. Vitamin A and iron status are improved by vitamin A and iron supplementation in pregnant Indonesian women. Journal of Nutrition 2002; 132(7): 1909-12.

37 Gleason GR, Sharmanov T. Anemia prevention and control in four central Asian republics and Kazakhstan. Journal of Nutrition 2002; 132(Suppl. 4): 867S-70S. 